Theme: Eletric Steelworks

\title{
BATH LEVEL MEASUREMENT SYSTEM IMPROVES EAF MELTING PROCESS CONTROL*
}

\author{
Patrik Bloemer ${ }^{1}$ \\ Jan-Peter Nilsson ${ }^{2}$ \\ Anthony Lyons ${ }^{3}$ \\ Christer Carlsson ${ }^{4}$ \\ Ivo Filipovic ${ }^{5}$ \\ Moreno Guarise
}

\begin{abstract}
Reliable and accurate furnace bath level data during the melting process is invaluable for good decision making and furnace optimization, while obtaining such information rapidly and safely on a regular basis is of paramount importance. This paper shows how a melting process problem was identified as a concern, how a solution was sought and how a real-time measurement system was tested by simple modification to an existing temperature sampling manipulator. Also how, with furnace power on or off, taking reliable hot heel, fill and running levels could be used to assist melting control, aid decision making and improve safety.

Keywords: Bath level; Hot Heel; Electrode Power; Reliability.
\end{abstract}

\footnotetext{
Master of Science, Electrical Engineering, CEO, Agellis Group AB, Lund, Sweden. Master of Science, Electrical Engineering, Manager R\&D, Agellis Group $A B$, Lund, Sweden. $B E n g$, Electronics Engineering, Senior Sales, Agellis Group AB, Lund, Sweden. Master of Science, Metallurgy, Senior Sales, Agellis Group AB, Lund, Sweden. BEng, Mechanical Engineering, Project Manager, MORE, Gemona del Friuli, PU, Italy. Diploma, Electronics Engineering, Automation Engineer, MORE, Gemona del Friuli, PU, Italy.
}

* Technical contribution to the $45^{\text {th }}$ Steelmaking Seminar, May $25^{\text {th }}-28^{\text {th }}, 2014$, Porto Alegre, RS, Brazil. 


\section{INTRODUCTION [1-3]}

In the steel melting production process there have been many recent advances, including the introduction of modern comprehensive control systems. However there has been almost no advance in the methods employed to record furnace bath levels. These are normally calculated by weighing scrap, estimating hot heel, estimating refractory wear rates and checking tapped weights. No level is checked on a regular basis.

Agellis Group $A B$ originally developed a system for measurement in nonferrous furnaces in which measurement signals could be transferred to levels of different materials in the smelter bath such as ore/concentrate, slag and metal/matte.

As many of Agellis Group AB's other systems are used extensively for measurement in ferrous metals production, interest immediately arose from the steel industry to use the same technology to measure steel levels in an EAF, an area in their production process sadly lacking in reliable and accurate level measurement.

Agellis Group AB decided to make some modifications to the hardware and software of their smelter systems more application specific and easy to use at all times in an EAF. This new system is called the EMLI-FBL, where FBL stands for Furnace Bath Level.

The main reasons for using this technology in an EAF would be to:

- Measure the hot heel level before charging to know the starting bath level for correct charge weight, electrode height \& power, control of foaming slag creation and general EAF process optimization

- Measure the steel bath level before next scrap load to optimize the process and fill level

- Measure the steel bath level in continuously fed furnaces

- Measure the steel bath level to be able to optimize the positioning of oxygen and carbon injection lances and to increase safety when handling water cooled lances

- Measure the steel bath level during arcing in furnaces to keep track of melting process

- Manage and control steel bath level in order to reach shorter tap to tap times and optimize energy consumption

- Measure the steel level before and after tapping to combine with ladle weight to help ascertain EAF refractory wear rates via volume.

- Raise the mean value of tapped weight for all charges.

- Significantly increase the process stability with less variation between taps.

- Obtain a production increase evaluated to be in the order of $2 \%$.

To be able to see if EMLI-FBL could provide reliable and accurate bath level information a trial was organized together with the manipulator manufacturer MORE at the Nunki steel plant in Italy. MORE manufactures slag door manipulators that are mainly used for temperature measurement in the EAF. With a simple modification to the MORE CATFIS manipulator, steel level detection could be performed during a normal temperature measurement sequence.

* Technical contribution to the $45^{\text {th }}$ Steelmaking Seminar, May $25^{\text {th }}-28^{\text {th }}, 2014$, Porto Alegre, RS, Brazil. 


\section{OVERVIEW OF NUNKI STEEL S.p.A [1]}

MORE recommended the Nunki Steel Plant, San Giorgio di Nogaro, Italy, as they had good contacts with this company.

Nunki Steel S.p.A. belongs to the GIVA Group and is a plant that produces high quality forged carbon, high/low alloy and stainless steel ingots.

Their process route includes an 80t Electric Arc Furnace, Ladle Furnaces and Degassers.

The EAF operates a melting process that produces molten steel and operates a tapto-tap cycle made up of the following operations:

- Furnace charging

- Melting

- Refining

- De-slagging

- Tapping

- Furnace turn-around

The aim is for a tap-to-tap time of less than 60 minutes.

Nunki Steel has a MORE CATFIS robotic slag door manipulator for taking temperature samples at the EAF.

\section{TRIAL OBJECTIVE [1]}

The Trial Objective was to prove that accurate and reliable steel levels can be taken in an EAF by utilizing a lance sensor system attached to a robotic slag door manipulator and furthermore, to do so with the furnace in 'power-on' mode. The modification of an existing robotic manipulator currently being used to take temperature samples should be shown to be simple and, in any final design, would allow for all required measurements to be taken during the same immersion sequence.

The trial objective would be regarded as fulfilled technically at site when the trial equipment performance specification function as agreed between the parties was reached in ten (10) lance immersion sequences.

\section{PREPARATIONS - SYSTEM INSTALLATION [1]}

\subsection{Modification of the More CATFIS Lance [4]}

The standard CATFIS lance was exchanged for a shorter version due to the fact that the EMLI-FBL sensor tip is longer than the temperature tip normally used. The EMLIFBL sensor tip and the new lance were then connected together and mounted on the CATFIS manipulator.

* Technical contribution to the $45^{\text {th }}$ Steelmaking Seminar, May $25^{\text {th }}-28^{\text {th }}, 2014$, Porto Alegre, RS, Brazil. 

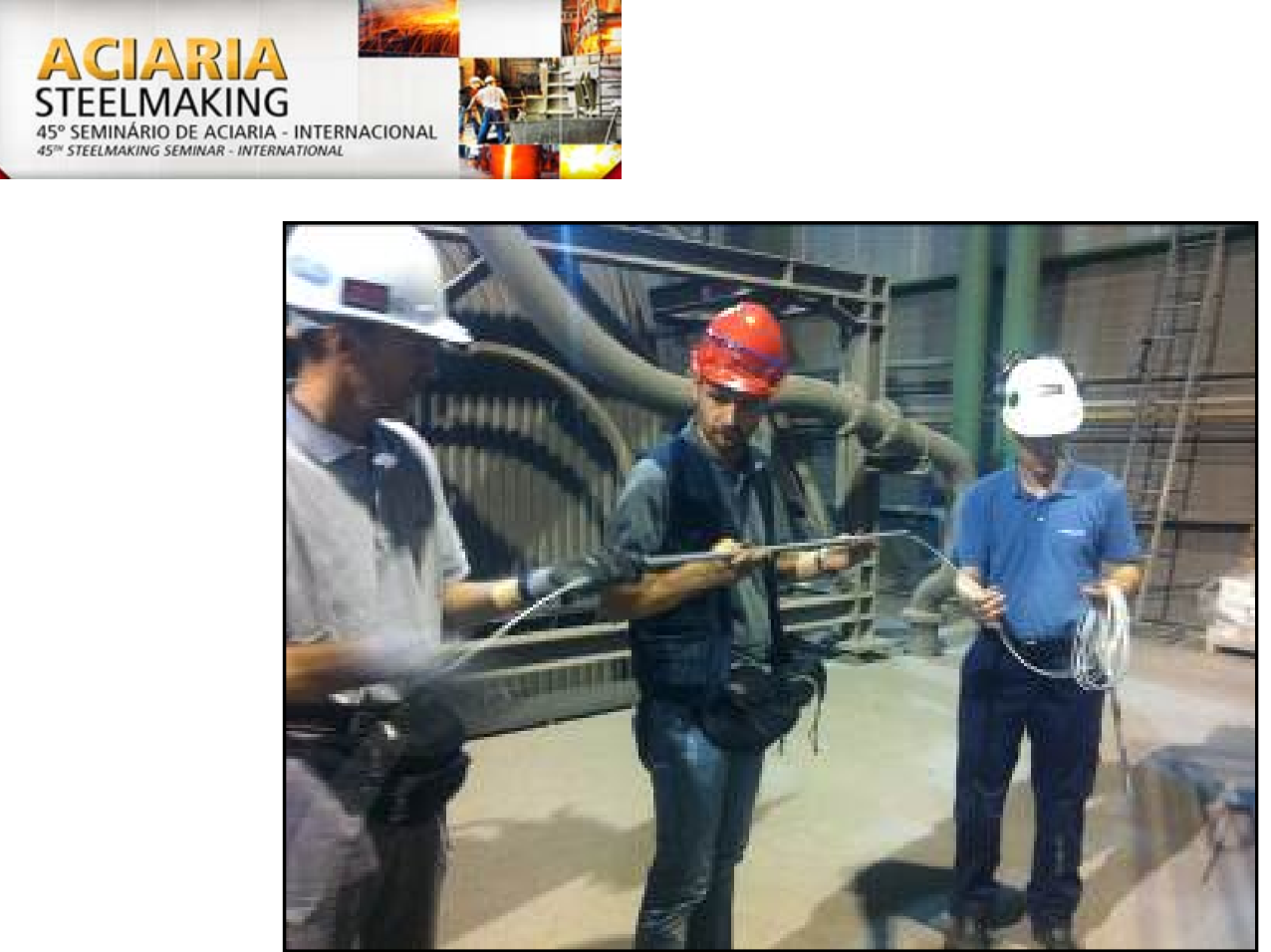

Figure 1. EMLI-FBL Lance cable insertion.

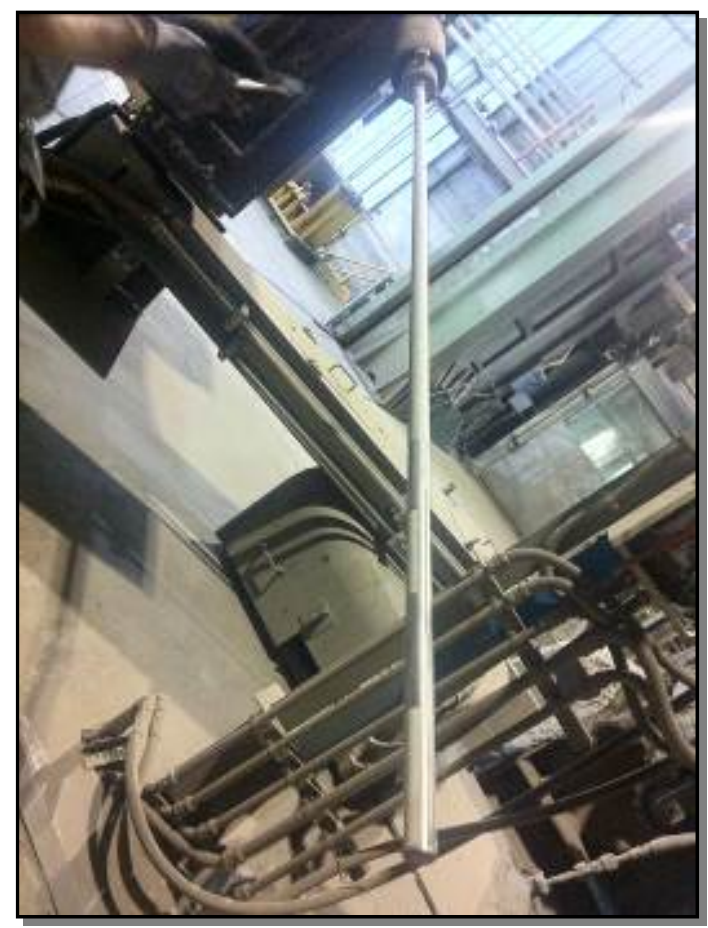

Figure 2. EMLI-FBL Lance attached to MORE manipulator.

\subsection{Sensor Cable}

The temperature measurement cable (orange) was removed and the same protection cover was used for the EMLI-FBL sensor cable (white).

* Technical contribution to the $45^{\text {th }}$ Steelmaking Seminar, May $25^{\text {th }}-28^{\text {th }}, 2014$, Porto Alegre, RS, Brazil. 

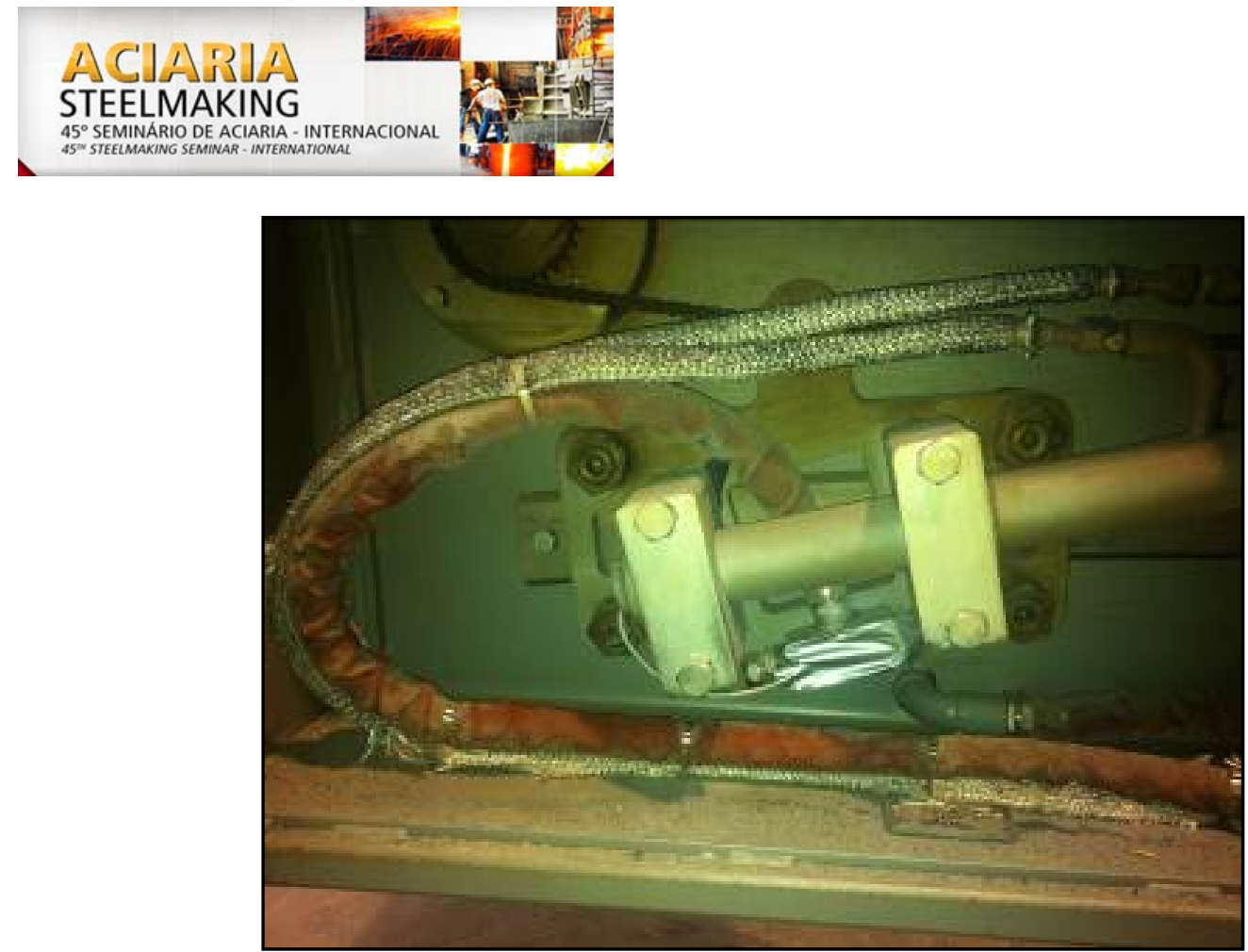

Figure 3. EMLI-FBL Sensor cables inside CATFIS manipulator.

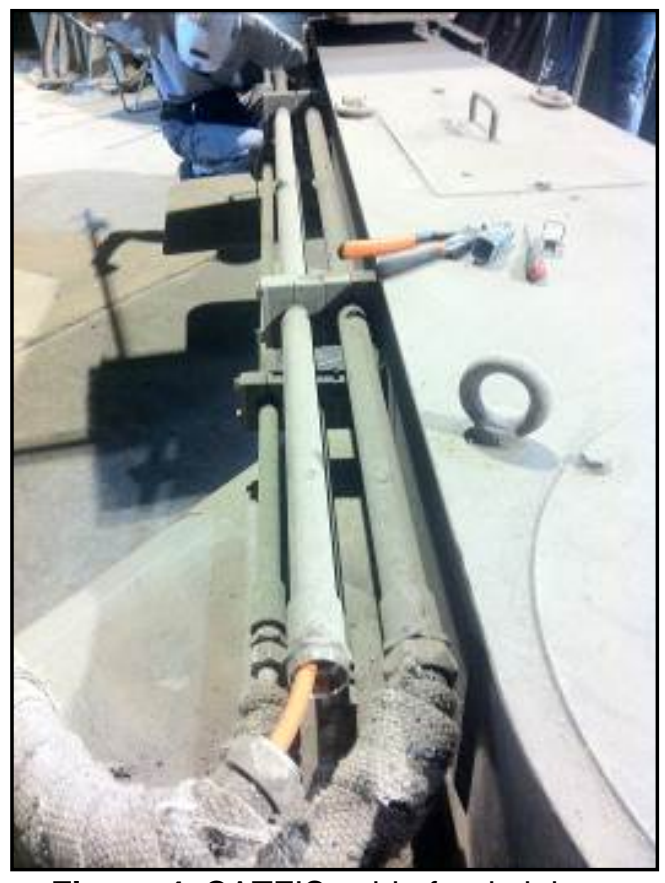

Figure 4. CATFIS cable feed piping.

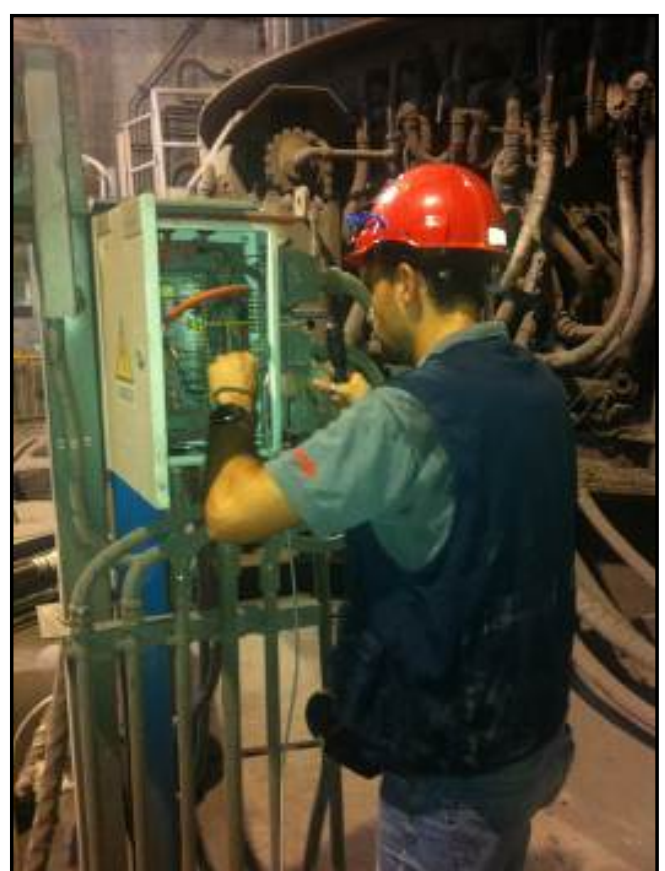

Figure 5. CATFIS encoder connections to EMLI-FBL.

\subsection{Lance Position \& Power Connection}

The EMLI-FBL system received the lance position signal from the MORE CATFIS $P L C$. The EMLI-FBL 4-20mA receiver was connected in series with the existing lance position 4-20mA loop.

In any measurement situation, to get a precise position of the EMLI-FBL sensor, first in relation to a manipulator reference point, and second, when immersed through the slag door, its position in relation to the EAF reference point, requires cooperation with the manipulator supply company. To get the vertical position of the lance it is required to use a translation table for lance position versus lance height.

* Technical contribution to the $45^{\text {th }}$ Steelmaking Seminar, May $25^{\text {th }}-28^{\text {th }}, 2014$, Porto Alegre, RS, Brazil. 


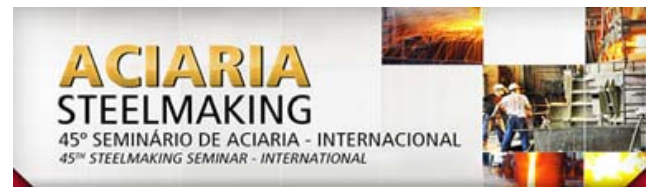

Finally a 230V AC Power Supply connection was provided by the plant and the CATFIS manipulator with EMLI-FBL measurement capability was ready.
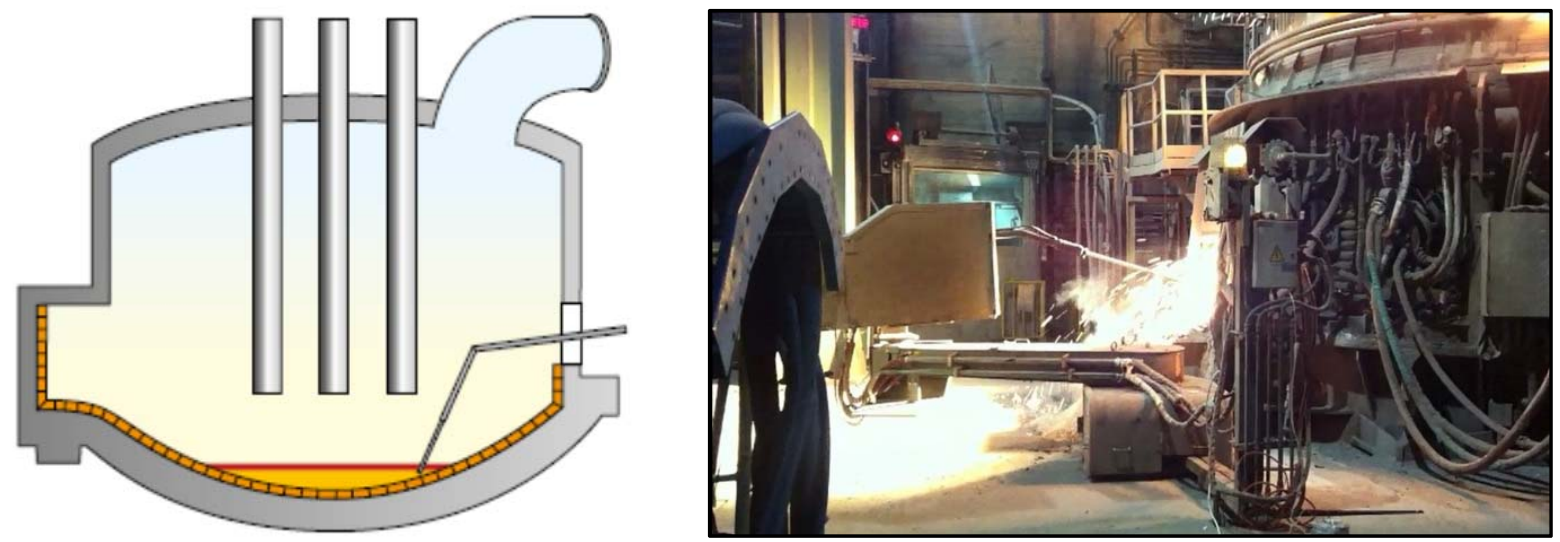

Figure 6. EMLI-FBL Lance on MORE manipulator [1,2].

5 THE TRIAL $[1,5]$

The trial was divided into 3 different measurement periods. In each period 2 dips were taken with furnace at full power (power on) and 2 dips were taken with no power (power off). In total 12 dips were taken and they were all successful.

Measurements were deliberately taken to try to cover different melting phases in the process.

The first round of dips started 20:56 and ended 21:01. This round was taken during the first heat of the day between the second and the third melting phase.

The second round of dips started 21:20 and ended 21:25. This round was taken during the first heat of the day after the third and last melting phase.

The third round of dips started 23:07 and ended 23:11. This round was taken during the second heat of the day after the last melting phase.

During the first 'power on' dip it became obvious that the measurement was affected by the noise from the electrodes. Although this meant that the normal EMLI-FBL detection software program function could not be used as it was currently configured, measurement data was still available.

So after some investigations of the data received, a manual detection method was implemented by the Agellis engineers so as to be able to use the available signals to successfully provide level information.

\section{MEASUREMENT RESULTS [1,5]}

The measurement results can be seen in the table below. The 'Lance Position at Detection' column shows how far the lance had travelled before the steel was detected. A higher number indicates that the lance travelled further and thus the surface of the steel was lower in the furnace.

* Technical contribution to the $45^{\text {th }}$ Steelmaking Seminar, May $25^{\text {th }}-28^{\text {th }}, 2014$, Porto Alegre, RS, Brazil. 


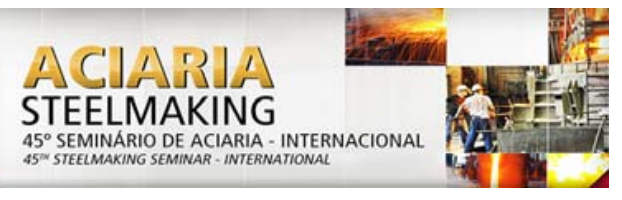

\begin{tabular}{|c|c|c|}
\hline Time & Lance Position at Detection & Comment \\
\hline $20: 56: 14$ & $\mathbf{8 0 9}$ & Dip 01 Round 1 Power On \\
\hline $20: 57: 20$ & $\mathbf{7 9 4}$ & Dip 02 Round 1 Power On \\
\hline $20: 59: 21$ & $\mathbf{8 0 1}$ & Dip 03 Round 1 Power Off \\
\hline $21: 00: 26$ & $\mathbf{8 0 5}$ & Dip 04 Round 1 Power Off \\
\hline $21: 20: 31$ & $\mathbf{6 0 8}$ & Dip 05 Round 2 Power On \\
\hline $21: 21: 37$ & $\mathbf{6 0 5}$ & Dip 06 Round 2 Power On \\
\hline $21: 23: 34$ & $\mathbf{6 2 8}$ & Dip 07 Round 2 Power Off \\
\hline $21: 24: 45$ & $\mathbf{6 2 8}$ & Dip 08 Round 2 Power Off \\
\hline $23: 07: 23$ & $\mathbf{7 6 9}$ & Dip 09 Round 3 Power On \\
\hline $23: 08: 24$ & $\mathbf{7 4 3}$ & Dip 10 Round 3 Power On \\
\hline $23: 09: 18$ & $\mathbf{7 3 8}$ & Dip 11 Round 3 Power Off \\
\hline $23: 10: 15$ & 747 & Dip 12 Round 3 Power Off \\
\hline
\end{tabular}

Figure 7. Measurement results

As seen in the table the measurement results are very good. It should be noted that the level accuracy is much better than the lance position indication (although that accuracy is already very good) due to the fact that the lance does not travel vertically. The data indicates that the EMLI-FBL system should be able to measure the steel level in this furnace with the power on with an accuracy of a few $\mathrm{mm}$. The turbulent surface of the steel will most likely be the limiting factor on how accurate this system can be.

The measurements can be validated in two ways.

1) The measurements within each round of sensor immersions are very consistent both in power on and power off modes. This proves that the system can measure the true steel level in both conditions.

2) The difference between the detection position between round 1 and round 2 shows that the system measures a much higher steel level in round 2 than in round 1 which is correct, since the furnace was fed with scrap that melted between those two measurements.

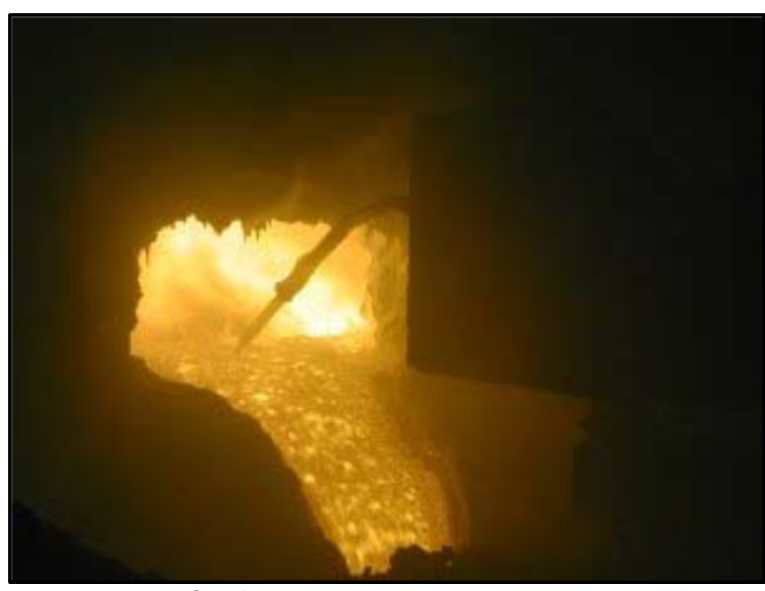

Figure 8. Catfis manipulator in operation.

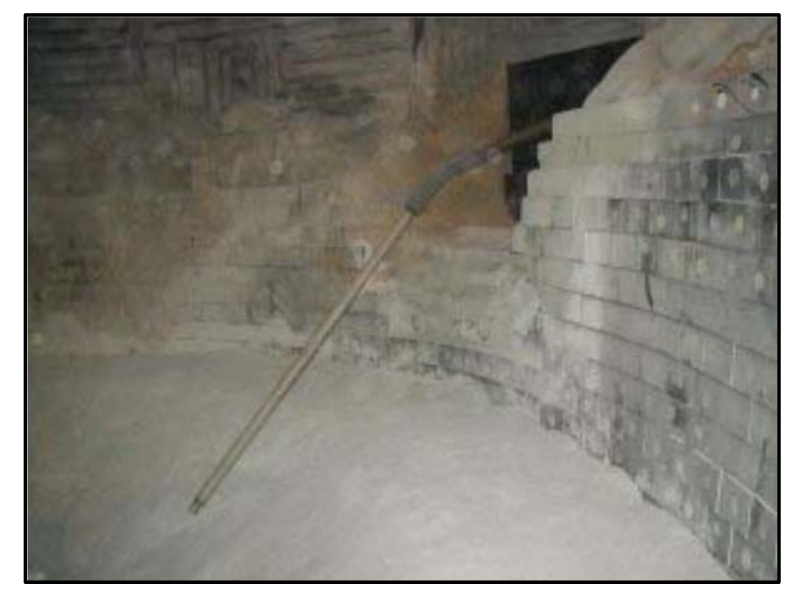

Figure 9. Probe position in empty furnace.

Figures below shows signals recorded during bath level measurement taken during trial sequence at Nunki Steel EAF. Green trace denotes sensor position during immersion sequence and blue trace shows bath level detection.

* Technical contribution to the $45^{\text {th }}$ Steelmaking Seminar, May $25^{\text {th }}-28^{\text {th }}, 2014$, Porto Alegre, RS, Brazil. 


\section{ACIARIA \\ STEELMAKING}

$45^{\circ}$ SEMINÁRIO DE ACIARIA - INTERNACIONAL

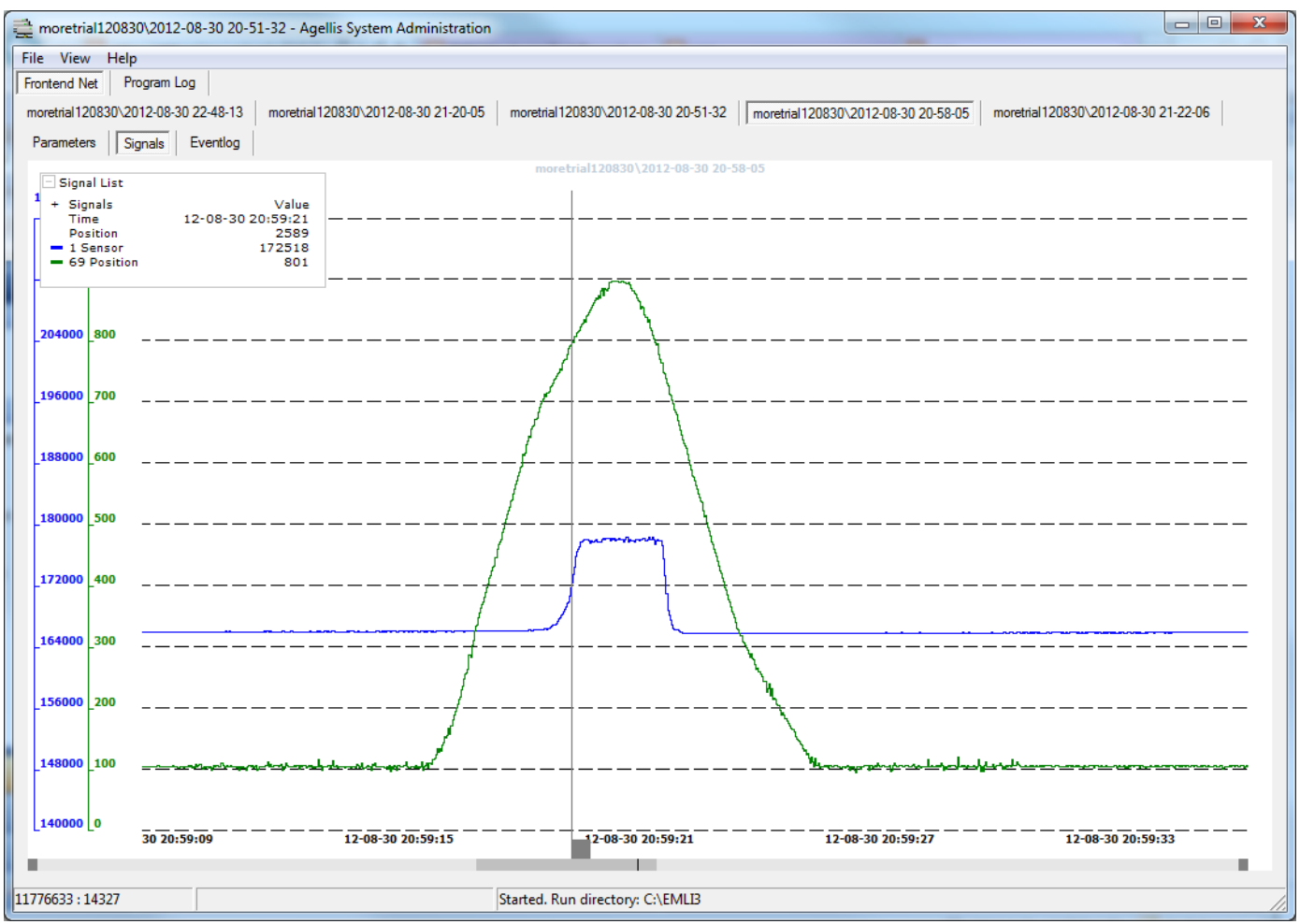

Figure 10. Recorded measurement signals example 1 Nunki Steel September 2012.

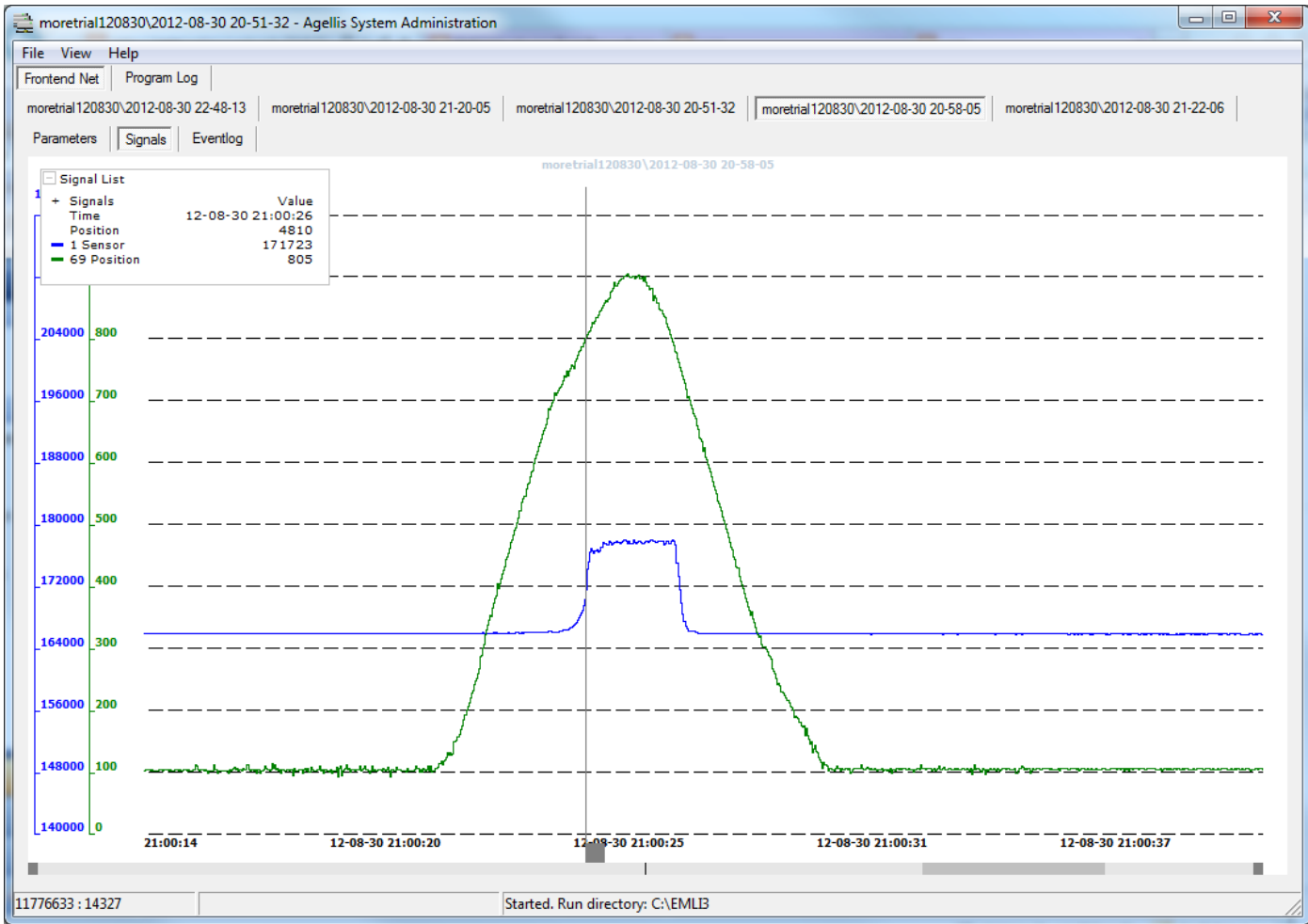

Figure 11. Recorded measurement signals example 2 Nunki Steel September 2012.

* Technical contribution to the $45^{\text {th }}$ Steelmaking Seminar, May $25^{\text {th }}-28^{\text {th }}, 2014$, Porto Alegre, RS, Brazil. 

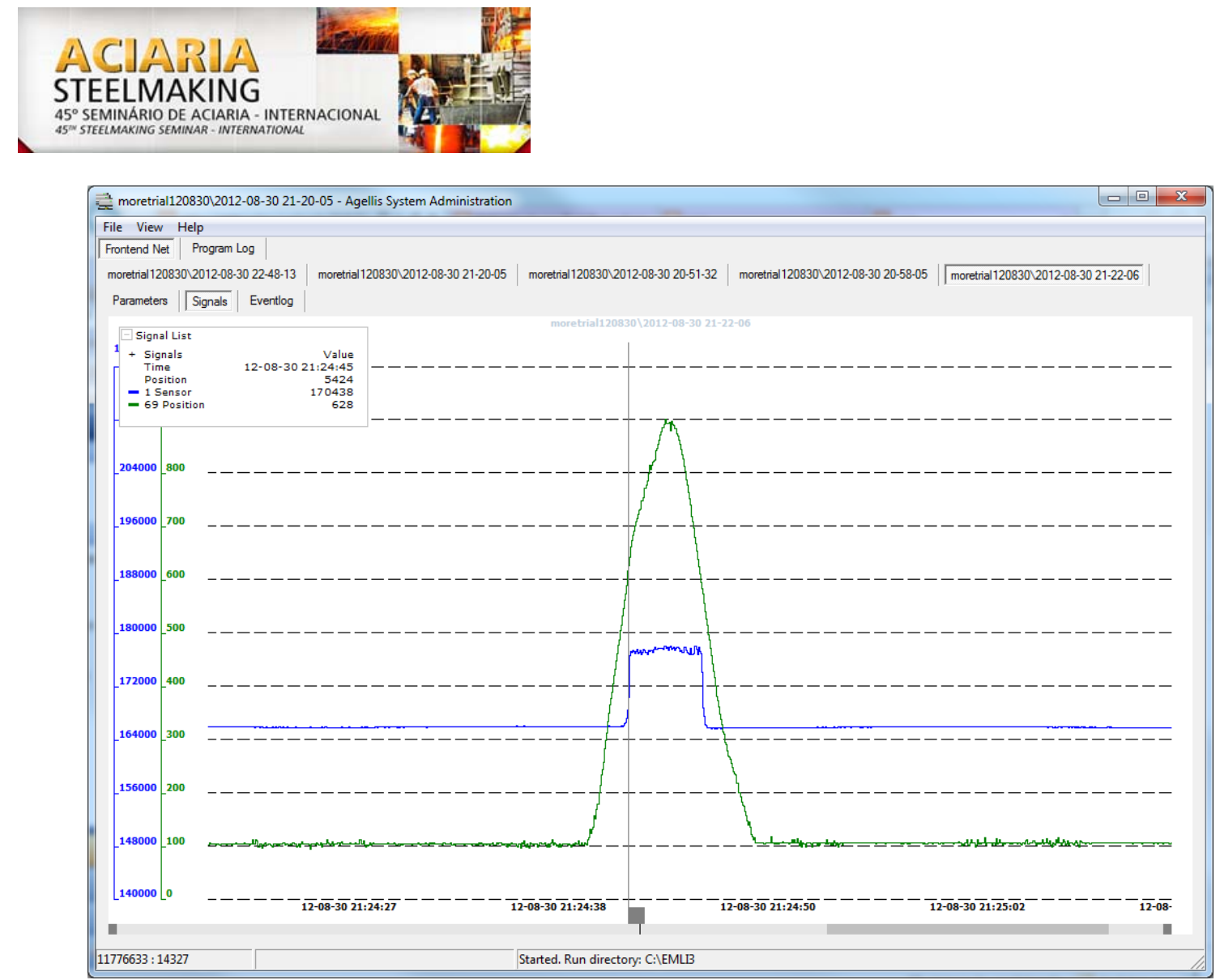

Figure 12. Recorded measurement signals example 3 Nunki Steel September 2012.

\section{CONCLUSIONS $[1,4,5]$}

A significant problem for steelmakers during melting in an EAF is how to know what amount of steel you actually have in your vessel at critical times. It is very important that the amount of steel being produced relates well to the amount that can be tapped at one time, to the amount of hot heel required to be left in the furnace after tapping and to the optimisation of the melting process including scrap charging points, additions, electrode height/power, injector positioning and melt time.

Most operators rely on visual indicators, experience and information about scrap charged and metal tapped. While the methods used by the operators to keep track of what they have in their vessel at any one time works as a general rule, it relies heavily on the human factor.

When an EAF is tapped the ladle is filled to a level that leaves a certain amount of freeboard at the top, so that further process operations can be carried out without overflow and loss of metal occurring.

This means that at the end of each melting sequence there must be enough metal to fill the ladle to the correct point and enough residual metal remaining in the bottom of the furnace (hot heel) to assist with the rapid melting of further scrap that will be charged at the next heat.

For the melting process to be optimised the operators need to know how much scrap and additions to charge into the furnace and to do that correctly they need to know what was their starting point. In other words, what is their hot heel?

At other points in the melting process such as between scrap charges and at or near the end of melting, the operators also need to know what they have in their vessel.

When the electrodes are arcing and the oxy-burners are running the operators would like to know where the steel level is in relation to the foaming slag being created.

Therefore the need for measurement in an EAF is a necessity for furnace process optimization.

* Technical contribution to the $45^{\text {th }}$ Steelmaking Seminar, May $25^{\text {th }}-28^{\text {th }}, 2014$, Porto Alegre, RS, Brazil. 


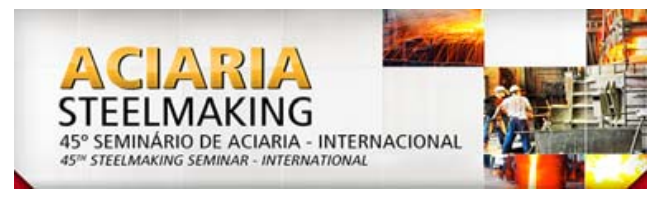

In running this successful trial at Nunki Steel Agellis Group AB \& MORE s.r.I have proven that:

- Accurate and reliable measurement of steel bath levels in a furnace is indeed both possible and practical under steel plant conditions.

- Measurements can be performed utilising existing technology with furnace power on or power off, with no disruption or change to the existing steel production process.

- This type of measurement system can be easily attached to slag door manipulators or roof entry delivery mechanisms, it can be referenced to any point on the furnace structure or surroundings and its output is easily linked to plant PLCs.

Furthermore, since the Nunki Steel trial, Agellis Group AB has proven the EMLI-FBL system in full production at other plants using various manipulator types and in conjunction with different measurement probes (temperature/oxygen/sample). The results have all been excellent with both electrode power off and electrode power on. A very good feature of the system is that a level measurement is acquired for each dip made in the furnace. It doesn't matter if the reason for the dip is sampling, temperature or oxygen content. The level data is taken during all of these operations. There are two advantages to this from a measurement point of view. More than one level indication is made per heat and the mean value of all the individual measurements should be more accurate than any individual measurement. Also, from a safety point of view, no extra operations have to be performed at the furnace and no extra time has to be spent in the danger zone in order to get a level measurement.

\section{Acknowledgements}

This paper is published by permission of MORE s.r.I., NUNKI Steel S.p.A. and Agellis Group AB. The contributions of our colleagues are gratefully acknowledged.

\section{REFERENCES}

1 Boemer P, Nilsson J-P. Agellis Emli Elp Eaf Test at Nunki Steel, OPR/REP/02746/AG, Sept. 2012.

2 Agellis Data Sheets. Emli-Fbl Com/Des/002737 Rev A \& Emli-Elp Com/Des/001379 Rev C.

3 Görnerup, M. Value of bath level measurement in EAF, Sept. 2013

4 More Brochure. Catfis Sampling and measuring lance manipulator operated through the slag door, Dec. 2010.

5 Nilsson J-P. Agellis Emli-Fbl Trial Report, OPR/REP/03111/AG, Oct. 2013.

* Technical contribution to the $45^{\text {th }}$ Steelmaking Seminar, May $25^{\text {th }}-28^{\text {th }}, 2014$, Porto Alegre, RS, Brazil. 